\title{
Screening of sugarcane genotypes for resistance against sugarcane early shoot borer, Chilo infuscatellus Snellen
}

\author{
Umashankar H.G. ${ }^{1 *}$, Patel V.N. ${ }^{2}$, Nagaraja T. ${ }^{3}$, Vijaykumar L. ${ }^{4}$, Sugeetha. $\mathbf{S}^{5}$
}

\author{
${ }^{1}$ M.Sc Scholar, Department of Agricultural Entomology, University of Agricultural Sciences Bengaluru, Karnataka, India \\ ${ }^{2}$ Prof. AICRP on Sugarcane, Zonal Agricultural Research Station, VC Farm Mandya-571405 \\ ${ }^{3}$ Prof. \& Scheme Head, AICRP on Sugarcane, Zonal Agricultural Research Station, VC Farm Mandya-571405 \\ ${ }^{4}$ Asst. Prof. College of Agriculture, VC Farm Mandya-571405 \\ ${ }^{5}$ Asst. Prof. College of Agriculture, VC Farm Mandya-571405
}

*Corresponding author

\begin{abstract}
In vivo experiment was conducted to screen fifty six genotypes for resistance to early shoot borer, Chilo infuscatellus Snellen at Zonal agricultural research station, V.C farm, Mandya during 2014-2015. The per cent incidence of ESB at different days after planting was varied among fifty six screened genotypes. The highest per cent incidence was recorded at 60 DAP (0.00 to 41.29) followed by at $30 \mathrm{DAP}$ (0.00 to 20.15) and the per cent incidence at 90 DAP ranged from 0.00 to 14.24 and lowest per cent incidence was recorded at 120 DAP (0.00 to 4.40). Based on the cumulative incidence, 47 genotypes were categorized as less susceptible to $C$. infuscatellus. Nine genotypes were found moderately susceptible to C. infuscatellus. However, among less susceptible genotypes lowest cumulative incidence of 0.00 per cent was recorded in genotypes, 0960-06. Whereas highest cumulative incidence of $29.86 \mathrm{per}$ cent was recorded in moderately susceptible genotype, 1038-06.
\end{abstract}

Keywords - Chilo infuscatellus, Early shoot borer, Genotypes, Per cent incidence, Resistance.

\section{INTRODUCTION}

In sugarcane based on feeding habit, the insect pests are broadly classified as borers, sucking pests, subterranean pests, defoliators and non-insect pests. Nine species of lepidopteran pests regularly damage sugarcane (David, 1977) in India. Among the borers, early shoot borer (ESB), Chilo infuscatellus Snellen is an important pest and is widely distributed in all sugarcane growing areas in the country. It infests the crop during early stages prior to internode formation. It also infests millable cane during years of drought or scanty rainfall. Borer infestation during the germination phase kills the mother shoots resulting in drying of entire clump and creating gaps in the field. But when the attack occurs during tillering phase, the clumps do not get killed although the crop stand is affected by mortality of tillers and loss in yield due to late formed canes with reduced weight and sucrose contents (Krishnamurthy Rao, 1954).

It has been computed that the shoot borer destroys 23-65 per cent mother shoots and 6.4, 27.1 and 75 per cent primary, secondary and tertiary tillers respectively (Doss, 1956; Khan and Krishanamurthy Rao, 1956). As reported by Patil and Hapase (1981) the ESB can cause a loss to the extent of 22-33 per cent in yield, 12 per cent in sugar recovery, two per cent in commercial cane sugar and 27 per cent in jaggery.

Several control methods have been evaluated from time to time. Among the different management strategies, the use of resistant genotype is one of the important components of IPM. So different genotypes have been screened under natural conditions to identify the less susceptible genotype for early shoot borer. Plant resistance is the most economical and desirable method in the management of crop pests. The use of resistant genotypes has proven to be the most efficient way to reduce the economic damage caused by early shoot borer. Among the screened genotypes the mechanism that imparts resistance to early shoot borer were investigated. Knowledge on resistance mechanism and associated factors involved is essential for effective utilization of source of resistance which is useful in future breeding programme. 


\section{MATERIAL AND METHODS}

Preliminary study on field screening of 56 genotypes was done to identify the less susceptible clones against ESB, $C$. Infuscatellus during 2014 at Zonal Agricultural Research Station, V.C Farm, Mandya. Three budded setts of 56 genotypes with known check CoVC 99463 and Co 86032 were obtained from Plant Breeding Department, AICRP on Sugarcane, Mandya.

The experiment was laid out in a randomised block design with fiftysix genotypes and was replicated twice. All agronomic practices were carried out as per the package of practices recommended for sugarcane cultivation by UAS, Bangalore (Anon., 2011).

Based on the per cent cumulative incidence of ESB, genotypes were graded according to Rao and Krinshamoorthy (1973).

\section{Dead heart counts}

Number of dead hearts caused by early shoot borer out of the total number of tillers observed in all the entries at 30, 60, 90 and 120 days after planting (DAP) was recorded.

After each count, the dead hearts were pulled out to avoid counting them later on.

The per cent incidence of ESB, Chilo infuscatellus was calculated by using the formula

$$
\text { Per cent incidence }=\frac{\text { Number of dead hearts }}{\text { Total number of tillers }} X 100
$$

Cumulative per cent incidence of ESB, Chilo infuscatellus

The cumulative per cent incidence was worked out by relating the progressive total of infested tillers (deadhearts) in proportion to the total number of tillers (Sithanantham, 1973) at 120 DAP.

Based on the cumulative per cent incidence, the sugarcane varieties were grouped in to three categories (Rao and Krinshamoorthy, 1973).

\section{Grade/Category}

Less susceptible (LS)

Moderately susceptible (MS)

Highly susceptible (HS)
Cumulative per cent incidence

$0-15$ per cent

15-30 per cent

$>30$ per cent

Table.1: Cumulative incidence of ESB, C. infuscatellus in different Sugarcane genotypes during 2014-15 at Zonal Agricultural Research Station, V.C. Farm, Mandya

\begin{tabular}{|c|c|c|c|c|c|c|}
\hline \multirow{2}{*}{$\begin{array}{l}\text { Sl. } \\
\text { No }\end{array}$} & \multirow{2}{*}{ Genotypes } & \multicolumn{4}{|c|}{ \% Incidence of ESB } & \multirow{2}{*}{$\begin{array}{c}\text { Cumulative } \\
\text { Incidence }\end{array}$} \\
\hline & & 30 DAP & 60 DAP & 90 DAP & 120 DAP & \\
\hline 1 & $09-60-06$ & $0.00(0.00)$ & $0.00(0.00)$ & $0.00(0.00)$ & $0.00(0.00)$ & $0.00(0.00)$ \\
\hline 2 & Co 0323 & $0.00(0.00)$ & $0.96(3.66)$ & $0.36(2.24)$ & $0.42(2.40)$ & $0.87(6.68)$ \\
\hline 3 & $09-65-02$ & $0.00(0.00)$ & $0.00(0.00)$ & $1.72(6.90)$ & $0.85(4.73)$ & $1.29(8.38)$ \\
\hline 4 & $11-02-09$ & $0.00(0.00)$ & $1.96(7.36)$ & $0.50(2.64)$ & $0.24(1.82)$ & $1.35(8.62)$ \\
\hline 5 & $7-62-01$ & $0.00(0.00)$ & $1.72(6.73)$ & $1.01(5.23)$ & $0.84(4.79)$ & $1.78(9.79)$ \\
\hline 6 & $10-28-16$ & $2.18(5.53)$ & $1.13(5.59)$ & $0.00(0.00)$ & $0.39(2.31)$ & $1.84(9.78)$ \\
\hline 7 & $09-60-28$ & $0.00(0.00)$ & $0.00(0.00)$ & $2.70(8.52)$ & $1.10(5.39)$ & $1.90(10.06)$ \\
\hline 8 & $10-28-08$ & $2.38(5.79)$ & $0.81(3.35)$ & $0.80(4.68)$ & $0.74(4.50)$ & $2.36(10.87)$ \\
\hline 9 & $11-11-06$ & $0.00(0.00)$ & $4.11(10.70)$ & $0.60(2.89)$ & $0.48(2.58)$ & $2.59(11.84)$ \\
\hline 10 & Co62175 & $0.00(0.00)$ & $2.33(8.04)$ & $1.59(6.61)$ & $1.37(6.15)$ & $2.64(12.08)$ \\
\hline 11 & 09-61-05 & $1.09(3.89)$ & $1.29(5.97)$ & $3.06(8.84)$ & $0.76(4.58)$ & $3.10(12.84)$ \\
\hline 12 & $10-12-14$ & $1.47(4.54)$ & $2.09(7.62)$ & $1.50(4.58)$ & $1.19(4.08)$ & $3.12(13.15)$ \\
\hline 13 & 009-64 & $0.00(0.00)$ & $0.00(0.00)$ & $4.86(10.65)$ & $1.62(6.72)$ & $3.24(12.82)$ \\
\hline 14 & $12-41-25$ & $0.00(0.00)$ & $4.09(10.42)$ & $2.27(7.76)$ & $0.50(2.62)$ & $3.43(13.81)$ \\
\hline 15 & $10-33-16$ & $2.68(8.60)$ & $0.41(2.39)$ & $3.40(9.60)$ & $1.17(5.71)$ & $3.83(14.55)$ \\
\hline 16 & VCF 0517 & $1.11(3.94)$ & $2.85(8.93)$ & $3.04(9.19)$ & $1.22(5.80)$ & $4.11(15.09)$ \\
\hline 17 & $10-17-08$ & $4.05(7.60)$ & $0.50(2.64)$ & $4.58(11.23)$ & $0.80(4.62)$ & $4.97(16.53)$ \\
\hline 18 & 09-10-03 & $4.80(11.47)$ & $1.25(5.85)$ & $2.97(9.05)$ & $1.13(5.60)$ & $5.08(16.82)$ \\
\hline 19 & $10-38-07$ & $2.38(5.79)$ & $1.25(4.18)$ & $4.20(10.85)$ & $2.59(8.50)$ & $5.21(16.79)$ \\
\hline 20 & $7-82-10$ & $1.57(4.68)$ & $6.93(13.66)$ & $1.20(5.76)$ & $1.09(5.49)$ & $5.39(17.01)$ \\
\hline 21 & $11-23-05$ & $0.00(0.00)$ & $9.11(16.00)$ & $1.13(5.55)$ & $0.71(3.13)$ & $5.47(17.27)$ \\
\hline 22 & 10-65-01 & $5.32(11.93)$ & $0.60(2.89)$ & $4.51(10.93)$ & $0.75(4.56)$ & $5.59(17.68)$ \\
\hline
\end{tabular}




\begin{tabular}{|c|c|c|c|c|c|c|}
\hline \multirow{2}{*}{$\begin{array}{l}\text { Sl. } \\
\text { No }\end{array}$} & \multirow{2}{*}{ Genotypes } & \multicolumn{4}{|c|}{$\%$ Incidence of ESB } & \multirow{2}{*}{$\begin{array}{c}\text { Cumulative } \\
\text { Incidence }\end{array}$} \\
\hline & & 30 DAP & 60 DAP & 90 DAP & 120 DAP & \\
\hline 23 & $10-20-06$ & $8.55(15.61)$ & $1.96(7.37)$ & $0.75(3.22)$ & $0.47(2.56)$ & $5.86(18.07)$ \\
\hline 24 & $10-43-06$ & $3.04(9.17)$ & $3.34(9.61)$ & $4.83(11.57)$ & $2.18(7.66)$ & $6.69(19.32)$ \\
\hline 25 & $10-14-17$ & $0.00(0.00)$ & $4.91(11.66)$ & $6.59(13.61)$ & $1.96(7.39)$ & $6.73(19.41)$ \\
\hline 26 & $08-04-01$ & $3.45(6.99)$ & $3.84(10.36)$ & $1.82(5.05)$ & $4.40(11.11)$ & $6.75(19.42)$ \\
\hline 27 & $10-35-04$ & $0.98(3.70)$ & $9.08(16.11)$ & $3.27(9.39)$ & $1.58(6.59)$ & $7.45(20.45)$ \\
\hline 28 & $09-65-04$ & $4.43(10.66)$ & $4.29(10.98)$ & $4.38(11.09)$ & $2.37(7.29)$ & $7.74(20.83)$ \\
\hline 29 & $11-11-02$ & $6.95(13.97)$ & $3.75(10.19)$ & $3.62(9.82)$ & $1.45(6.22)$ & $7.88(20.83)$ \\
\hline 30 & 09-63-01 & $7.79(14.76)$ & $1.60(6.63)$ & $4.28(10.40)$ & $2.13(7.35)$ & $7.90(20.64)$ \\
\hline 31 & $10-38-15$ & $0.00(0.00)$ & $7.83(14.60)$ & $5.48(12.26)$ & $2.50(8.36)$ & 7.91(21.04) \\
\hline 32 & 09-29-04 & $6.20(12.99)$ & $5.67(12.65)$ & $3.24(9.23)$ & $0.82(3.38)$ & $7.96(21.06)$ \\
\hline 33 & 09-61-07 & $0.00(0.00)$ & $6.12(13.05)$ & $8.54(15.58)$ & $1.43(6.26)$ & $8.05(21.20)$ \\
\hline 34 & $09-30-01$ & $6.67(13.64)$ & $7.59(14.60)$ & $1.81(6.94)$ & $0.87(4.79)$ & $8.46(21.76)$ \\
\hline 35 & $10-14-16$ & $4.51(10.99)$ & $2.25(7.91)$ & $9.62(16.15)$ & $2.49(7.34)$ & $9.44(22.40)$ \\
\hline 36 & $07-21-04$ & $8.71(15.57)$ & $2.34(7.85)$ & $4.89(11.57)$ & $3.24(9.52)$ & $9.59(22.97)$ \\
\hline 37 & $07-10-02$ & $2.04(7.55)$ & $10.69(17.48)$ & $5.53(12.37)$ & $2.19(7.78)$ & $10.57(24.41)$ \\
\hline 38 & $10-28-02$ & $1.47(4.54)$ & $12.47(18.66)$ & $2.87(8.95)$ & $3.26(9.51)$ & $10.03(23.72)$ \\
\hline 39 & $09-60-10$ & $11.23(17.94)$ & $5.98(12.88)$ & $2.24(7.83)$ & $1.07(5.40)$ & $10.26(24.04)$ \\
\hline 40 & $09-60-08$ & $11.31(17.91)$ & $3.03(8.65)$ & $6.70(13.77)$ & $0.00(0.00)$ & $10.52(24.15)$ \\
\hline 41 & 09-60-04 & $14.69(20.25)$ & $3.81(10.19)$ & $2.02(7.25)$ & $0.93(5.03)$ & $10.72(24.50)$ \\
\hline 42 & $10-14-15$ & $11.30(17.97)$ & $5.76(12.74)$ & $4.82(11.64)$ & $1.12(3.95)$ & $11.50(25.42)$ \\
\hline 43 & $10-20-08$ & $13.07(19.46)$ & $8.30(15.33)$ & $1.22(4.13)$ & $1.48(4.55)$ & $12.03(26.09)$ \\
\hline 44 & $10-38-08$ & $0.00(0.00)$ & $7.13(14.20)$ & $14.24(20.36)$ & $3.73(10.13)$ & $12.55(26.61)$ \\
\hline 45 & $10-57-07$ & $7.68(14.41)$ & $11.52(17.93)$ & $4.36(9.77)$ & $1.74(4.94)$ & $12.65(25.83)$ \\
\hline 46 & 09-61-02 & $3.70(7.25)$ & $20.76(24.89)$ & $3.62(10.03)$ & $1.61(6.66)$ & $14.85(28.99)$ \\
\hline 47 & $10-58-05$ & $9.96(16.76)$ & $15.54(20.73)$ & $3.24(9.18)$ & $2.04(7.46)$ & $15.38(29.55)$ \\
\hline 48 & $10-17-05$ & $11.90(18.46)$ & $10.01(16.88)$ & $5.79(12.74)$ & $3.07(9.14)$ & $15.39(29.57)$ \\
\hline 49 & $07-06-05$ & $4.89(11.28)$ & $15.00(20.36)$ & $11.78(17.75)$ & $1.30(5.68)$ & $16.48(30.30)$ \\
\hline 50 & $10-33-33$ & $7.11(14.15)$ & $23.28(26.33)$ & $4.31(11.00)$ & $0.81(3.36)$ & $17.75(31.76)$ \\
\hline 51 & $10-20-11$ & $19.76(23.94)$ & $13.44(18.70)$ & $3.19(9.34)$ & $1.35(5.94)$ & $18.87(32.34)$ \\
\hline 52 & $08-15-06$ & $16.30(21.66)$ & $26.43(28.14)$ & $7.97(14.62)$ & $1.06(3.85)$ & $25.88(38.73)$ \\
\hline 53 & 06-09-03 & $20.85(24.78)$ & $25.47(27.64)$ & $8.01(14.98)$ & $0.57(2.81)$ & $27.45(39.77)$ \\
\hline 54 & $10-38-06$ & $2.78(6.26)$ & $41.29(36.52)$ & $12.84(18.89)$ & $2.81(8.78)$ & $29.86(41.04)$ \\
\hline 55 & Co99463 & $5.16(12.04)$ & $0.49(2.60)$ & $2.86(8.93)$ & $1.15(5.66)$ & $4.83(16.41)$ \\
\hline 56 & Co 86032 & $10.57(15.86)$ & $27.92(28.97)$ & $4.55(11.00)$ & $1.74(6.79)$ & $22.39(35.09)$ \\
\hline \multicolumn{2}{|c|}{$\mathrm{SEm} \pm$} & 2.5 & 3.7 & 1.9 & 0.7 & 1.5 \\
\hline \multicolumn{2}{|c|}{$\mathrm{CD} @ \mathrm{P}=0.05$} & 7.2 & 10.5 & 5.4 & 2.1 & 4.2 \\
\hline
\end{tabular}

\section{RESULTS AND DISCUSSION}

Studies on the field screening of 56 genotypes were carried out to identify the less susceptible genotypes against ESB, Chilo infuscatellus. Genotypes were graded as less susceptible (LS), moderately susceptible (MS) and highly susceptible (HS) based on the per cent incidence of ESB at 30, 60, 90, 120 DAP and based on cumulative per cent incidence of ESB upto 120 days after planting.
The overall per cent incidence of ESB at 30 DAP in all the screened genotype ranged from 0.00 to 20.85 . Based on the per cent incidence of ESB at 30 days after planting, fifty three genotypes were categorized into less susceptible category including two standard checks viz., Co 99463 (5.16\%) and Co 86032 (10.57\%). Among these 53 less susceptible genotypes viz., 09-61-07, 009-64, 10-14-17, 0960-06, 09-60-28, 10-38-08, 11-02-09, 11-23-05, 7-62-01, 12-41-25, 11-11-06, 10-38-15, Co323, 09-65-02 and 
Co62175 recorded zero per cent incidence at 30 days after planting. Whereas the genotypes viz., 08-15-06 (16.30\%), 10-20-11 (19.76\%) and 06-09-03 (20.85\%) were classified into moderately susceptible group. None of the genotypes fell under highly susceptible category (Table 1). It was found that most of the genotypes were found free from the incidence of ESB. This might be due to fast growth of the genotypes which might have helped the genotypes to escape from the ESB incidence. Similar observations were also made by Gupta and Avasthy (1954c); Kalra and Chaudhary (1964).

Incidences of ESB at 60 DAP in all the screened genotypes ranged from 0.00 to $41.29 \%$. Among the fifty six genotypes, 48 genotypes including the standard check Co $99463(0.49 \%)$ were graded as least susceptible (LS) and the genotypes 009-64, 09-60-06, 09-60-28 and 09-65-02 found to be highly resistant to ESB with the 0.00 per cent incidence. Six genotypes 10-58-05 (15.54\%), 09-61-02 (20.76\%), 10-33-33 (23.28\%), 06-09-03 (25.47\%) and 0815-06 (26.43\%) including standard check Co 86032 $(27.92 \%)$ fell under moderately susceptible category. The genotype 10-38-06 with $41.29 \%$ of ESB incidence was classified as highly susceptible group at 60 days after planting. The genotypes 08-15-06 and 06-09-03 which were moderately susceptible at 30 days after planting remained as MS group even at 60 days after planting (Table 1). The per cent incidence of ESB had increased at sixty days after planting. The per cent incidence steadily increased from $30^{\text {th }}$ to $90^{\text {th }}$ day and thereafter it declined. This is in confirmation with the findings of Sithanatham et al., 1975 wherein the young crop of 30 to 60 days age is reported to be susceptible to this pest. Rao and Siva (1962) also reported Chilo infuscatellus Snellen, preference to 45 days old plants for ovipostion. This is in line with the findings of present study.

At 90 days after planting, the per cent incidence of ESB in all the genotypes decreased. The incidence ranged from 0.00 to $14.24 \%$. All the genotypes including both the checks CoVC 99463 (2.86\%) and Co 86032 (4.55\%) were found less susceptible (LS). The incidence of ESB was maximum in the genotype 10-38-08 (14.24\%). The genotypes 10-28-16 and 09-60-06 were found to be less susceptible to ESB at 90 days after planting by registering 0.00 per cent incidence (Table 1).

Similarly at 120 days after planting the per cent incidence of ESB decreased further. The per cent incidence of ESB at 120 DAP in all the screened genotype ranged from 0.00 to $4.40 \%$. All the 56 genotypes fell under less susceptible categories including two standard checks with incidence ranging from 0.00 to 4.44 per cent. Highest incidence was recorded in genotype 08-04-01 (4.40\%). The genotypes 0960-06 and 10-28-16 registered 0.00 per cent incidence at 120 days after planting (Table 1). At 90 and 120 days after planting, the per cent incidence of ESB in all the genotypes decreased. All the genotypes including both standard checks Co 99463 (2.86\%) and Co 86032 (4.55\%) were found least susceptible (LS). It is due to the fact that all genotypes have inherent capacity to produce more number of tillers, thereby reducing the shoot borer incidence. This is in agreement with the findings of Doss (1956), Khanna (1956) and Rao and Rao (1961).

The overall cumulative per cent incidence of ESB in all the screened genotype ranged from 0.00 to $29.86 \%$. Among the 56 genotypes, 47 genotypes were graded as less susceptible including the standard check Co 99463 (4.83\%). The genotype 09-60-06 was found to be highly resistant to ESB with cumulative ESB incidence of 0.00 per cent. The cumulative ESB incidence was less than two percent in five genotypes (09-65-02, 11-02-09, 7-62-01, 10-28-16 and 0960-28). The nine genotypes fell under the category of moderately susceptible including the check Co 86032 $(22.39 \%)$. None of the genotypes fell under highly susceptible category. The overall cumulative incidence of ESB ranged from 0.00 to 29.86 per cent. The highest cumulative incidence of ESB was recorded in genotypes 0815-06 (25.88\%), 06-09-03 (27.45\%) and 10-38-06 (29.86\%) (Table 1). The highest cumulative incidence of ESB was recorded in genotypes 08-15-06 (25.88\%), 06-09-03 $(27.45 \%)$ and $10-38-06$ (29.86\%). Similar results were also reported by the earlier workers Rajendran and Giridharan (2001), Kumar et al., 2002 and Bhavani et al., 2011.

\section{CONCLUSION}

The results of field screening of different genotypes for resistance to ESB revealed that the genotypes viz., 009$64(3.44 \%), \quad 10-65-01(5.59 \%), \quad 10-65-01(3.83 \%), 10-17-$ 08(4.97\%), 10-57-07(12.65\%), 07-10-02(10.57\%), 10-28$02(10.03 \%)$ and 09-61-02(14.85\%) which recorded less than 15 per cent of incidence were graded as least susceptible while genotypes 10-17-05(15.39\%), 07-0605(16.48\%), 10-33-33(17.75\%), 10-38-06(29.86\%), 08-15$06(25.88)$ and $06-09-03(27.45)$ have recorded 15 to 30 per cent incidence of ESB were graded as moderately susceptible (MS), whereas check Co 99463(4.83\%) and Co 86032(22.39\%) have recorded per cent incidence of ESB.

\section{ACKNOWLEDGEMENTS}

The authors are thankful to the AICRP on sugarcane, at Zonal agricultural research station, V.C farm, Mandya for providing all the facilities during the research work. 


\section{REFERENCES}

[1] DAVID, H., 1977, Pests of sugarcane and their control. Pestol., 1: 15-19.

[2] DOSS, S. N. J., 1956, Incidence of sugarcane borers in Nellikuppam factory zone, South Arcot, Madras state. Proc. Int. Soc. Sug. Cane Technol., 9: 880-895.

[3] KHAN, M. Q. AND RAO, B. H. K., 1956, Assessment of loss due to Chilotraea infuscatellus Snell. Proc. Int. Soc. Sug. Cane Technol., 9: 870-879.

[4] PATIL, A. S. AND HAPASE, D. G., 1981, Research on sugarcane borers in Maharashtra. Proc. National Symp. on Stalk Borer, Karnal, pp.165-1758.

[5] ANONYMOUS, 2011, Zonal Research and Extension Programme Workshop. University of Agriculture Sciences, Bangalore.

[6] RAO, S. AND KRISHNAMURTHY RAO M. M., 1973, Studies on loss in yield of sugarcane due to shoot borer incidence, Chilo infuscatellus snellen (Pyralidae : Lepiodoptera). Indian Sug., 22: 867-868.

[7] SITHANANTHAM, S., 1973, Performance of some new organic insecticides in the control of sugarcane shoot borer Chilo infuscatellus snellen. Indian Sug., 22: 933-938.

[8] GUPTHA, B. D. AND AVASTHY, P. N., 1957, An epidemic of cane borer, Chilo tumidicostalis Hmpsn. Indian J. Sug. Cane Res. Dev., 22: 3.

[9] KALRA, A. N. AND CHAUDHARY, 1964, Infructuous attack of top borer of sugarcane. Indian $\mathrm{J}$. Sug. Cane Res. Dev., 8: 261-264.

[10] SITHANANTHAM, S., DURAI, D. AND MUTHUSAMY, S., 1975, Incidence of sugarcane shoot borer in relation to planting time. Indian Sug., 24: 867-870.

[11]RAO, AND SIVA, D. V., 1962, Studies on the resistance of sugarcane to the early shoot borer, Chilo infuscatellus Snell. M.Sc Thesis, Andhra University, waltair.

[12] KHANNA, K. L., 1956, On tiller mortality and compensation due to borers in sugarcane. Proc. Int. Soc. Sug. Cane Technol., 9: 936-971.

[13] RAO, N. V. S. AND RAO, C. K., 1961, Preliminary studies on varietal resistance of sugarcane to infestation by the early shoot borer, Chilotraea infuscatellus Snell., Andhra Agri. J., 8: 140-146.

[14] RAJENDRAN，B. AND GIRIDHARAN, S., 2001, Field screening of sugarcane clones against shoot borer. Indian. Sug. 51(8): 515-516.

[15] KUMAR, A., SINGH, A. K., SINGH, A. P., SINGH, S. K., AND SINGH, P. R., 2002, Response of sugarcane world germplasm against shoot borer (Chilo infuscatellus Snellen) infestation. Coop. Sug., 34(2): 131-134.

[16] BHAVANI, B., REDDY, K. D., RAO, N. V. AND LAKSHMI, M. B., 2012, Biochemical basis for antibiosis mechanism of resistance in sugarcane to early shoot borer, Chilo infuscatellus Snellen. Trop. Agr. Research., 23(2): 126 - 141. 